\title{
Metzler Autoren Lexikon
}

Deutschsprachige Dichter und Schriftsteller

vom Mittelalter bis zur Gegenwart 


\section{Metzler}

Autoren

\section{Lexikon}

Deutschsprachige Dichter und Schriftsteller vom Mittelalter bis zur Gegenwart

Mit 425 Abbildungen

Zweite, überarbeitete und erweiterte Auflage

Ungekürzte Sonderausgabe

Herausgegeben von Bernd Lutz

Verlag J. B. Metzler

Stuttgart $\cdot$ Weimar 


\section{Inhaltsverzeichnis}

Vorwort $\mathrm{V}$

Autoren A-Z 1

Weiterführende Bibliographie 886

Verzeichnis der Mitarbeiterinnen und Mitarbeiter 888

Personenregister 892

Bildquellen 905

Die Deutsche Bibliothek - CIP-Einheitsaufnahme

Metzler-Autoren-Lexikon : deutschsprachige Dichter und Schriftsteller vom Mittelalter bis zur Gegenwart /

hrsg. von Bernd Lutz. - Ungekürzte Sonderausg.,

2., überarb. und erw. Aufl.

- Stuttgart ;Weimar : Metzler, 1997

ISBN 978-3-476-01573-0

ISBN 978-3-476-01573-0

ISBN 978-3-476-03720-6 (eBook)

DOI 10.1007/978-3-476-03720-6

Dieses Werk einschließlich aller seiner Teile ist urheberrechtlich geschützt. Jede Verwertung außerhalb der engen Grenzen des Urheberrechtsgesetzes ist ohne Zustimmung des Verlages unzulässig und strafbar. Das gilt insbesondere für Vervielfältigungen, Übersetzungen, Mikroverfilmungen und die Einspeicherung und Verarbeitung in elektronischen Systemen.

(C) 1997 Springer-Verlag GmbH Deutschland

Ursprünglich erschienen bei J. B. Metzlersche Verlagsbuchhandlung und Carl Ernst Poeschel Verlag GmbH in Stuttgart 1997 


\section{Vorwort zur ersten Auflage}

Wer sich als Literaturleser einen Eindruck von den Daten, den Lebensumständen, dem Lebensplan, dem literarischen Konzept und den wesentlichen Werken eines Autors der deutschen Literaturgeschichte verschaffen möchte, ist auf zwei Auskunftsmittel angewiesen: die zahlreichen Literaturgeschichten, die alten und die neuen, und die dazu vorhandenen biographischen Lexika. Relativ rasch wird man zu der Einsicht gelangen, daß weder die Literaturgeschichten noch die biographischen Lexika einen anschaulichen und faßbaren Begriff der Persönlichkeit des Autors vermitteln. Die Literaturgeschichten können diesen Anspruch nicht erfüllen, weil sie das Subjektive übergreifende Momente der Sozialgeschichte, der literarischen Institutionen, der Gattungsgeschichte und der literarischen Kommunikation in den Vordergrund $\mathrm{zu}$ stellen haben. Die biographischen Lexika dagegen setzen ihren Ehrgeiz in die möglichst vollständige Nennung der annähernd 3000 Autoren, die bekannt geworden sind - wo sie sich nicht räumlich oder zeitlich von vornherein Beschränkungen auferlegen. Zuletzt sehen sie sich allesamt zu bedenklichen Vereinfachungen gezwungen: Die Daten zu Leben und Werk werden ohne thematischen Zusammenhang bekanntgegeben; aufgrund der notwendigen Verknappung fallen literarhistorische Werturteile fast zwangsläufig plakativ aus; eine Gewichtung wesentlicher Autoren der deutschen Literaturgeschichte gegenüber den kleineren Lichtern drückt sich allenfalls über die Menge der nur in der Nähe größerer Bibliotheken zugänglichen Sekundärliteratur aus, mit der die einzelnen Artikel substanziell untermauert werden sollen.

Mit der Konzeption dieses Lexikons deutschsprachiger Autorinnen und Autoren ist der Versuch gemacht, die Verfahrensweisen der Literaturgeschichte und der Biographik lebendig und eindringlich miteinander zu verbinden. Das Konzept dieses Buches kann gewinnen, wo es der Literaturgeschichte gegenüber zu verstehen gibt, daß es mit dem reflektierenden Zugriff, der Darstellung des "literarischen Prozesses " allein nicht getan ist, wenn es um die Erfassung der Fülle und der Zufälligkeiten des literarischen Lebens geht. Dadurch ist ein Buch zustande gekommen, das viel Verständnis für das mitunter Rätselhafte und Bizarre der schriftstellerischen Existenz abverlangt. Die Schar der schreibenden Höflinge und Rebellen, der Alkoholiker und Drogensüchtigen, der Weiberhelden und der Verfechter asketischer Ideale, der lechzenden Ämteraspiranten und der saturierten Couponschneider legt alles andere als den verklärenden Eindruck von den "Leiden großer Meister" nahe. Die beabsichtigte erzählerische Intensität der einzelnen Artikel mußte zwangsläufig zu Lasten der Vollständigkeit gehen. Es werden daher nur diejenigen Autoren behandelt, die in der Literaturgeschichte im allgemeinen Rang und Namen haben. Daß das Feld interessanter Autorinnen und Autoren bei weitem nicht ausgeschöpft ist, wird insbesondere für das 19. und 20. Jahrhundert bewußt; doch waren hier, was Schreibkapazität, Umfang und Zeitpunkt der Fertigstellung des Buchs betreffen, rasch Grenzen erreicht, die einen ersten Einhalt geboten haben.

Dieses Buch stellt eine Gemeinschaftsleistung von über einhundert Literaturwissenschaftlern des In- und Auslands dar. Sie haben sich mit großer Umsicht und Geduld der Aufgabe gestellt, auf (letzten Endes doch wieder) knappem Raum "ihre " Autoren zur 
Geltung zu bringen. Sie haben dies umso bereitwilliger getan, als sie nicht nur einem raschen Informationsbedürfnis dienen, sondern vor allem zum "Weiterlesen«, zur Weiterbeschäftigung mit der schwierigen und vertrackten Sache der Literatur anregen wollen.

$\mathrm{Zu}$ danken ist denjenigen, die beim Zustandekommen des Buches geholfen haben: Heidi Oßmann, Christel Pflüger und Susanne Wimmer.

Stuttgart, im August 1986

Bernd Lutz

\section{Vorwort zur zweiten Auflage}

Das Metzler Autoren Lexikon ist zahlreich rezensiert und insgesamt als neuartiges lexikalisches Unternehmen begrüßt worden. Bemängelt wurden regelmäßig "fehlende " Autorinnen und Autoren, über die man gerne etwas gelesen hätte. Der Herausgeber der ersten Auflage war sich dieser Tatsache durchaus bewußt und hat deshalb von "einem ersten Einhalt" gesprochen, der gemacht werden mußte. Aufgrund des großen Erfolges konnte die zweite Auflage weiter ausgreifen, vor allem im 20. Jahrhundert und in der unmittelbaren literarischen Gegenwart. Das innerliterarische Beziehungsgeflecht ist damit dichter geworden. Mehr als eine "geglückte Auswahl« kann bei einem einbändigen Lexikon nicht gelingen, damit ein wenig Spiegel des Vermächtnisses der deutschen Literatur, deren Ausdrucksstärke unter einem abstrakten Vollständigkeitsanspruch sehr zu leiden begänne. An dieser Stelle ist für ihre tätige Mithilfe zu danken: Eva-Maria Eckstein, Martina Gronau, Heidi Oßmann, Andrea Rupp und Sigrun Zühlke. 